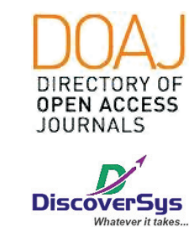

Published by DiscoverSys

\title{
Prevalence of anemia on chronic kidney disease and its influenced factors in Sanglah General Hospital 2015-2017, Bali
}

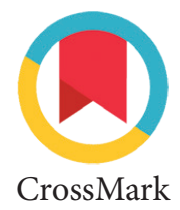

\author{
Rubahshini Gunaseelan, ${ }^{1 *}$ I Wayan Surudarma, ${ }^{2}$ \\ Desak Made Wihandani, ${ }^{2}$ I Wayan Gede Sutadarma²
}

\section{ABSTRACT}

Background: Anemia is the most common disease among chronic kidney disease (CKD) patients. Its prevalence increased gradually as kidney function decreased. Globally, it affects 1.62 billion people, which corresponds to $24.8 \%$ of the population.

Aim: To determine the prevalence of anemia on CKD and its influenced factors at Sanglah Hospital, Bali.

Method: This was a descriptive design study conducted in Sanglah General Hospital, Denpasar, Bali from 2015 until 2017. Medical records of the patients became the secondary data for this research.
Result: From 2015 to 2017, there were 384 cases of CKD and 95 were anemic in the hospital. The prevalence of this case was $24.7 \%$. The age group of 51 - 60 years had the highest case. The males majorly dominated anemia on CKD. Anemia in stage $V$ of CKD patients was the highest, and it increased more significant as the stages worsen, and diabetes was the leading underlying disease among anemia in CKD patients followed by CVD and glomerulonephritis. The hemoglobin level mean and glomerular filtration rate was lower than the normal one.
${ }^{1}$ Medical Science Study Program, Faculty of Medicine, Udayana University

2Department of Biochemistry, Faculty of Medicine, Udayana University
*Correspondence to: Rubahshini Gunaseelan, Medical Science Study Program, Faculty of Medicine, Udayana University rubahshinigunaseelan@gmail.com

Received: 2018-04-10 Accepted: 2018-08-24 Published: 2020-03-26
Keywords: Chronic kidney disease, anemia

Cite This Article: Gunaseelan, R., Surudarma, I.W., Wihandani, D.M., Sutadarma, I.W.G. 2020. Prevalence of anemia on chronic kidney disease and its influenced factors in Sanglah General Hospital 2015-2017, Bali. Intisari Sains Medis 11(1): 248-252. D0I: 10.15562/ism.v11i1.247

\section{INTRODUCTION}

Anemia was a condition that happened when the blood had insufficient red blood cells or had a shortage of hemoglobin due to this abnormality in the number of blood cells, or deformed blood cells as well as the lack of hemoglobin to bind to oxygen, tissues of the body can't get the oxygen they need and becomes asphyxiated. Fatigue, weakness, a fast or irregular heartbeat, shortness of breath, and pale skin are symptoms of anemia. ${ }^{1}$ Anemia may develop in the early stages of the disease when the patient has lowered kidney function $(20 \%$ to $50 \%)$. Anemia tends to worsen as CKD progresses. Patients who have a total loss of kidney function or total kidney failure need to go for regular dialysis as well as they prone to have anemia. Inadequate production of erythropoietin will lead to anemia. ${ }^{1}$

Erythropoietin (EPO) is a hormone produced by the kidneys which stimulate the bone marrow to produce red blood cells. Therefore, it is not sufficiently presented in kidney dysfunction. As a result of this abnormality, the bone marrow does not provide enough blood cells to keep up with the body's needs, and anemia occurred. A subcutaneous or intravenous injection of EPO is one of the recommended treatments to reduce anemia. This treatment is considered when the Hb level is less than $10 \mathrm{~g} / \mathrm{dl}$. Symptomatic therapy for CKD patients includes iron supplements as well as EPO. ${ }^{2}$

In the worldwide, CKD remains the leading cause of morbidity and mortality among the elderly population. The burden is disproportionately among the elderly from low-income and middle-income countries. Anemia is the most common disease among CKD patients. It has the worst prognosis among CKD patients compared to other conditions such as diabetes, hypertension, and cardiovascular disease. Prevalence of anemia increases gradually as kidney function decreased. There is plenty of complication comes along when there is anemia in CKD patients such as deficiency of EPO, the toxic effect of uremia on marrow precursor cells, reduced red cell survival, and increased blood loss due to capillary fragility and poor platelet function. It also has diminished intake, absorption, and utilization of dietary iron. Some studies had also stated that males acquire anemia on CKD more frequently as against to the females. Thus, anemia on CKD aggravates along with other diseases such as diabetes, cardiovascular diseases, and hypertension. ${ }^{3-5}$

Globally, anemia affects 1.62 billion people (95\% CI: $1.50-1.74$ billion), which corresponds to $24.8 \%$ of the population (95\% CI: 22.9-26.7\%). The highest prevalence is in preschool-age children (47.4\%, $95 \%$ 
CI: 45.7-49.1), and the lowest prevalence is in men (12.7\%, 95\% CI: 8.6-16.9\%). However, the population group with the highest number of individuals affected is non-pregnant women (468.4 million, 95\% CI: 446.2-490.6). Whereas, in Bali, the total prevalence of anemia patients according to $\mathrm{WHO}$ is $46.2 \%$. Thus, the research design to determine the prevalence of anemia on CKD among patients in Sanglah General Hospital, Denpasar, Bali.

\section{METHOD}

This was a descriptive cross sectional study using medical records of the patients as the secondary data from October 2015 to October 2017. This research discussed the prevalence and its influenced factors associated with CKD patients $(\mathrm{n}=384)$ in Sanglah General Hospital, Denpasar, Bali. The death patients' files were unable to access in the medical record department. Thus, the remaining sample in one year did not reach the sample requirement. Therefore, It was taken in 2 years due to the insufficient sample size within one year. From the overall data obtained, the survey showed that the CKD patients with anemia as many as 95 .

\section{RESULTS}

Table 1 showed that of the total 384 CKD patients, $95(24.7 \%)$ were anemia. As of 2016, there were 73 CKD patients with anemia and against 88 were without anemia. Whereas, since 2017, of 123 (32\%) CKD patients, 22 were anemia and not for remained 101.

\section{Age}

Figure 1 showed the number of anemia on CKD patients in the age group below than 30 years was

Table 1 Prevalence of CKD

\begin{tabular}{lccc}
\hline Type & $\mathbf{2 0 1 6}$ & $\mathbf{2 0 1 7}$ & Total $(\mathbf{n}=\mathbf{3 8 4})$ \\
\hline Anemia & 73 & 22 & $95(24.7 \%)$ \\
Non-anemia & 88 & 101 & $289(75.3 \%)$ \\
\hline
\end{tabular}

Table 2 Characteristic of the sample

\begin{tabular}{|c|c|c|}
\hline Variables & Total $(n=95)$ & $\%$ \\
\hline \multicolumn{3}{|l|}{ Age } \\
\hline$<30$ years & 10 & 11 \\
\hline $30-40$ years & 15 & 16 \\
\hline $41-50$ years & 14 & 15 \\
\hline $51-60$ years & 29 & 31 \\
\hline$>60$ years & 27 & 27 \\
\hline \multicolumn{3}{|l|}{ Gender } \\
\hline Males & 52 & 55 \\
\hline Females & 43 & 45 \\
\hline \multicolumn{3}{|l|}{ Stages of Chronic Kidney Disease } \\
\hline I & 4 & 4 \\
\hline II & 5 & 5 \\
\hline III & 10 & 11 \\
\hline IV & 24 & 25 \\
\hline $\mathrm{V}$ & 52 & 55 \\
\hline \multicolumn{3}{|l|}{ Other Associated Diseases } \\
\hline Diabetes & 30 & 32 \\
\hline Cardiovascular Diseases & 25 & 26 \\
\hline Hypertensive Nephropathy & 15 & 16 \\
\hline Glomerulonephritis & 20 & 21 \\
\hline Others & 23 & 24 \\
\hline Hemoglobin, $(\mathrm{g} / \mathrm{dl}$; mean $\pm \mathrm{SD})$ & $11.12 \pm 1.8(\mathrm{n}=32)$ & \\
\hline eGFR $(\mathrm{mL} / \mathrm{min} / 1.73 \mathrm{~m} 2 ;$ mean $\pm \mathrm{SD})$ & $27.9 \pm 13.5$ & \\
\hline
\end{tabular}




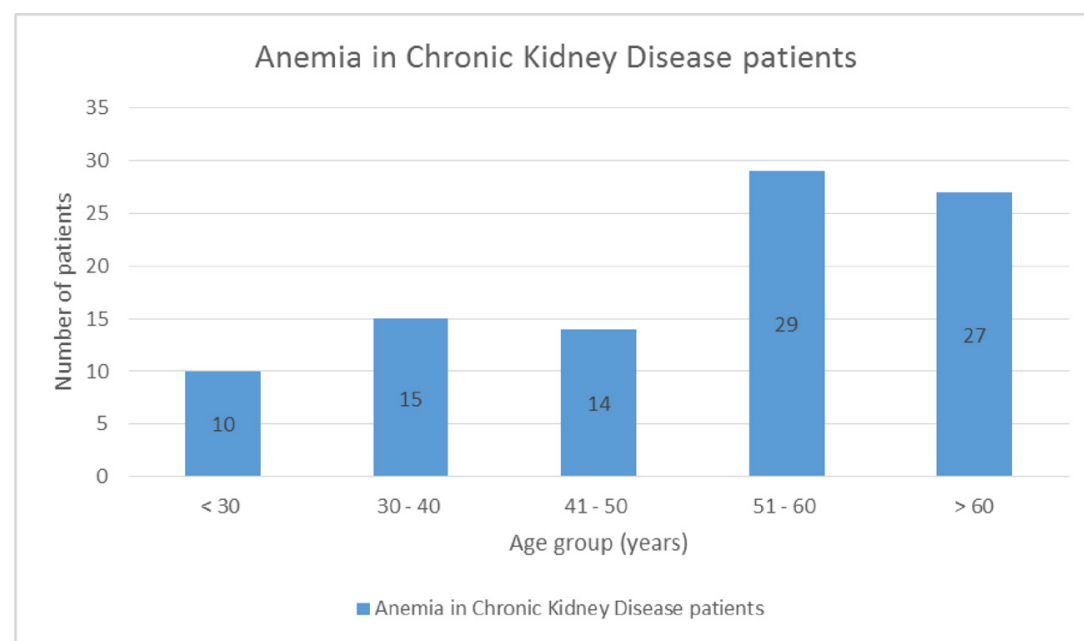

Figure 1 The number of anemia on CKD patients in each age groups

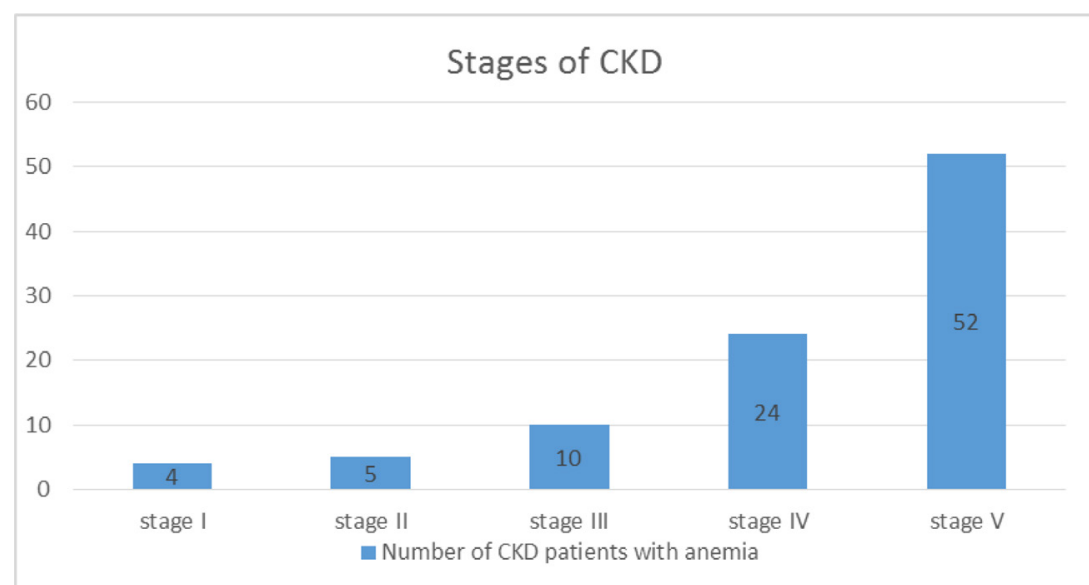

Figure 2 Stages of Chronic Kidney Disease patients who have anemia as stage I-V.

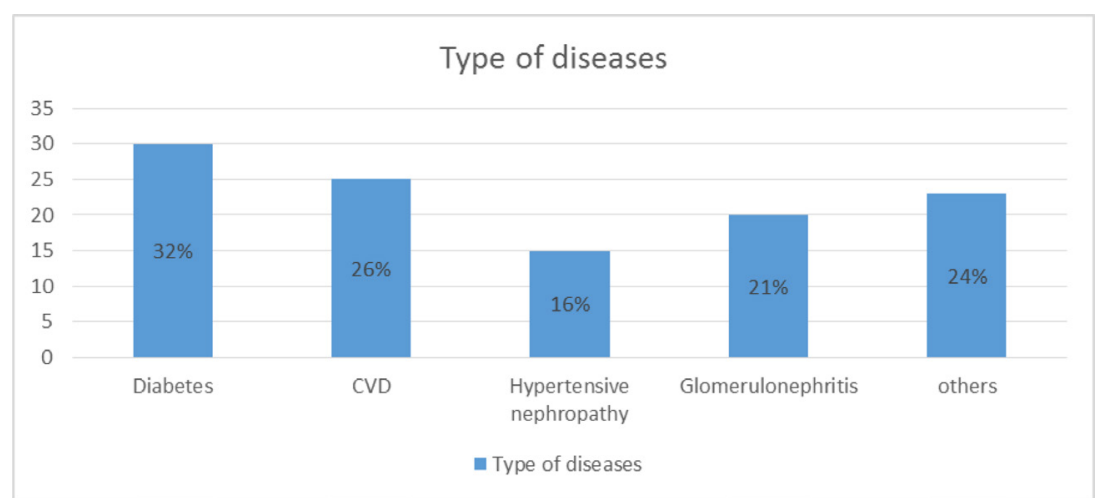

Figure 3 Variated type of diseases in subjects

10 people, 15 in $30-40$ years, 14 in $41-50$ years, 29 in 51-60 years, and 27 people above 60 years as well.

\section{Gender}

Of the 95 anemia on CKD patients, 52 were males which are $55 \%$, as against 43 were females 43 as recommended by the National Anemia Action Council and the World Health Organization. ${ }^{5}$

\section{Stages of Chronic Kidney Disease}

Of the 95 patients as shown in figure 2, 4 were in stage I, 5 were in II, 10 were in III, 24 were in IV, and 52 were in V. Based on figure 2, most of the anemia patients are in stage V. It seemed that prevalence of anemia increased with progressively deteriorating renal function as the stages increases.

According to the National Health and Nutrition Examination Survey (NHANES), the prevalence of anemia on CKD was $15.4 \%$. From this study, the prevalence of anemia on CKD was about $24.7 \%$. It is related to the burden of patients who require erythropoietin treatment might be considerably large. And the lifestyle difference can be one of the cause. $^{6}$

\section{Other Associated Diseases}

Of the 95 patients as shown in figure 3, 30 had diabetes, 25 had cardiovascular diseases, 15 had hypertensive nephropathy, 20 had glomerulonephritis, and 23 of them had many other associated diseases such as bone diseases, hypokalemia, pneumonia, stroke and protein-energy malnutrition. Moreover, some had more than one condition.

\section{DISCUSSION}

According to the National Health and Nutrition Examination Survey (NHANES), a higher prevalence of anemia on CKD was observed in US nursing home residents aged $>64$ with $\mathrm{CKD}$ stages $3-5$. By the age 40 , kidney filtration began to fall by approximately $1 \%$ per year. Thus, it would lead to anemia by decreasing the production of hemoglobin. ${ }^{6,7}$

Furthermore, the previous study showed that there were many cases of anemia on CKD among the $50-59$ age group where the prevalence of a rGFR of $<60 \mathrm{ml} / \mathrm{min} / 1.73 \mathrm{~m}^{2}$ was higher in the elderly compared to the young one. This study also clearly stated when the rGFR deteriorated, it led to inadequate erythropoietin levels due to kidney disease, the metabolic products of renal dysfunction, and the toxins produced by uremia. ${ }^{8}$ In Sanglah General Hospital, the most individuals with anemia were in the $51-60$ and 60 above. It was complicated to find the results specifically according to gender because many risk factors affected the studies based on each individual's exposure. Therefore, the male patients referred to those who had poor control of blood pressure, anemia, and proteinuria and so does the female. Proteinuria was the most crucial risk factor for male patients, and poor glycemic control was the crucial risk factor for female patients as well. ${ }^{9}$

According to Mabel et al., iron deficiency is highly prevalent in non-dialysis chronic kidney 
disease patients on ESA therapy. These findings reflected a lack of effective iron supplementation when managing anemia on pre-dialysis patients, especially in women at early stages and men at advanced stages. However, there was no proper study showed whether which gender was prominent among anemia on CKD patients. Thus, it was important to identify the other underlying factors to provide an appropriate management. ${ }^{10}$

According to the Okinawa General Health Maintenance Association (OGHMA) data, the prevalence of anemia increased as CKD progressed below an eGFR of $60 \mathrm{ml} / \mathrm{min}$ per $1.73 \mathrm{~m}^{2}$ in both genders. The association of lower kidney function with anemia was found to be more prevalent from approximately $50 \mathrm{ml} / \mathrm{min}$ per $1.73 \mathrm{~m}^{2}$. A previous study presented that among individuals with CKD, at all levels of GFR, anemia portended a poor prognosis and was associated with increased mortality compared to those individuals with preserved hemoglobin. The progression of anemia as the CKD stages increased can be the leading cause of death. ${ }^{11}$

According to previous biomedical research, it was found that as much as $17.64 \%$ in patients with stage I CKD and reaching $80 \%$ in patients with stage $\mathrm{V}$ CKD. A strong association between anemia and CKD was determined. Anemia on CKD was the established risk factor for the development of cardiovascular disease. Therefore, it was necessary to identify anemia on CKD as soon as possible and manage them properly before the development of cardiovascular disease. ${ }^{12}$

As to facilitate assessment of CKD severity and the National Kidney Foundation developed criteria, as part of its Kidney Disease Outcomes Quality Initiative (NKF KDOQI), it could stratify CKD patients such as the beginning stage 1: normal eGFR $\geq 90 \mathrm{~mL} / \mathrm{min}$ per $1.73 \mathrm{~m} 2$ and persistent albuminuria; stage 2: eGFR between 60 to $89 \mathrm{~mL} / \mathrm{min}$ per $1.73 \mathrm{~m} 2$; stage 3: eGFR between 30 to $59 \mathrm{~mL} / \mathrm{min}$ per $1.73 \mathrm{~m} 2$; stage 4: eGFR between 15 to $29 \mathrm{~mL} /$ min per $1.73 \mathrm{~m} 2$; stage 5 : eGFR of $<15 \mathrm{~mL} / \mathrm{min}$ per $1.73 \mathrm{~m} 2$ or end-stage renal disease. The prevalence of these stages of CKD in the US population was 1.8\% (stage 1), 3.2\% (stage 2), $7.7 \%$ (stage 3), and $0.35 \%$ (stages 4 and 5). Those with stage 3 or 4 might progress to End-Stage Renal Disease (ESRD) or stage 5 at a rate of $1.5 \%$ per year. ${ }^{13}$ A previous conceptual study correlated to the result obtained in Sanglah General Hospital where the prevalence of anemia of the study significantly increased with advancing CKD stages such as $22.4 \%$ at stage $1,30 \%$ in $2,51.1 \%$ in $3,79.2 \%$ in 4 , and stage 5 was $90.2 \%{ }^{14}$

In a cross-sectional study, a US multicenter survey of 2004, the prevalence of anemia was strongly associated with declining GFR $(8.4 \%$ at stage 1 to $53.4 \%$ at stage 5). ${ }^{7}$ However, it seemed that the prevalence of anemia significantly increased with advancing CKD stage where anemia on CKD aggravates the adverse outcomes in CKD and worsens along the stages of CKD, and it leads to ESRD.

Anemia is a significant cause of physical and mental impairments in diabetic CKD patients including malaise, fatigue, weakness, dyspnea, impaired cognition, and other symptoms. For example, in a 5-year prospective observational study conducted in a diabetes clinic in Australia, anemia was found in early kidney disease, and declining $\mathrm{Hb}$ levels were more common among those with higher levels of albuminuria. The distribution of $\mathrm{Hb}$ in patients with diabetes and CKD is similar to that in those without diabetes, but on average, $\mathrm{Hb}$ levels were lower in diabetes patients. Whereas, previous study, a total of 368 patients with CKD (Stages 2-4) were included in this study, forming two groups: The first group consisted of 184 patients with DM and CKD and the second group of 184 matched CKD patients without DM. A trend of increasing anemia prevalence was found with the progression of CKD from Stage 2 towards Stage 4, i.e., Stage 2, 9.6\%; Stage 3, 43.3\%; Stage 4, 54.8\% and anemia was present in 149 patients accounting for $40.5 \%$ of the total population studied. ${ }^{14-16}$

According to Moro O Salifu et al., glomerulonephritis condition is characterized by irreversible and progressive glomerular and tubulointerstitial fibrosis, ultimately leading to a reduction in the glomerular filtration rate (GFR) and retention of uremic toxins. If disease progression is not halted with therapy, the net results are CKD and ESRD. Chronic glomerulonephritis was the third leading cause of CKD where about $90 \%$ of patients progress to ESRD within weeks or months. According to $\mathrm{Li}$ et al. (2016), anemia was more prevalent in patients with diabetic nephropathy (68.0\%) than in patients with hypertensive renal damage (56.6\%) or chronic glomerulonephritis $(46.1 \%$, both $\mathrm{p}<0.001) .{ }^{17}$

According to study carried out by National Institute of Health (NIH), the increased CVD associated with ESRD estimated the anemia of CKD increases morbidity and mortality from cardiovascular complications (angina, left ventricular hypertrophy (LVH) and worsening heart failure), which may lead to further deterioration of renal function and the establishment of a vicious cycle termed the "cardiorenal anemia syndrome". 18 The presence of LVH is associated with decreased survival of patients on dialysis. End-stage renal disease patients with LVH have a 30\% lower fiveyear survival rate than individuals lacking LVH. Despite all this, anemia was an independent predictor of death in stable coronary artery disease patients with CKD. ${ }^{17}$ 


\section{CONCLUSION}

As of October 2015- October 2017, there were 384 cases of Chronic Kidney Disease (CKD) and 95 of them suffered anemia on CKD. The prevalence of anemia on CKD in Sanglah General Hospital was $24.7 \%$. The group of $51-60$ years had the highest prevalent. It was majorly dominated by the males. Diabetes was the leading underlying disease among anemia on CKD patients followed by CVD and glomerulonephritis. The mean hemoglobin level and glomerular filtration rate was lower than the regular reading.

\section{REFERENCES}

1. Iseksi K, Kohagura K. Anemia as a risk factor for chronic kidney disease. Dialysis Unit, University Hospital of The Ryukyus. Kidney Int 2007; 72: S4-S9

2. Weiner D. Anemia Management in Chronic Kidney Disease: Bursting the Hemoglobin Bubble. Annals of Internal Medicine 2010;153(1):532.

3. R.Bridges T. The University of Southern Mississippi The Aquila Digital Community. Awareness, Education, and Prevention of Chronic Kidney Disease in the Older Adult. 2014;5-2014:11-68.

4. Staples A, Wong C, Smith J, Gipson D, Filler G, Warady B et al. Anemia and Risk of Hospitalization in Pediatric Chronic Kidney Disease. Clinical Journal of the American Society of Nephrology. 2009;4(1):48-56.

5. Uzma M, Robert D.Toto. Anemia, diabetes and chronic kidney disease. Department of Nephrology, University of Texas Southwestern Medical Center; 2009:32

6. Swaraj. S Sunil. G, Poornima. V. Prevalence of anemia and cardiovascular diseases in chronic kidney disease patients: a single tertiary care centre study. International Journal of Advances in Medicine.2016;4(1):247-251

7. Stauffer ME, Fan T. Prevalence of Anemia in Chronic Kidney Disease in the United States. Moura IC, ed. PLoS ONE. 2014;9(1):e84943. doi: 10.1371/journal. pone.0084943.

8. Chen Y, Qin M, Zheng J, Yan H, Li M, Cui Y, et al. Hemoglobin discriminates the stages of chronic kidney disease in elderly patients. Experimental and Therapeutic Medicine. 2015;10(2):567-571
9. Chang $\mathrm{P}$, Chien L, Lin Y, Wu M, Chiu W, Chiou H. Risk factors of gender for renal progression in patients with early chronic kidney disease. Medicine. 2016;95(30):e4203

10. Aoun M, Karam R, Sleilaty G, Antoun L, Ammar W. Iron deficiency across chronic kidney disease stages: Is there a reverse gender pattern?. PLOS ONE. 2018;13(1):e0191541

11. Virani S, Khosla A, Levin A. Chronic kidney disease, heart failure, and anemia. Canadian Journal of Cardiology. 2008;24:22B-24B.

12. Bibek P, Binod KY, Bharat J, Kanak B, Dipendra R. Prevalence and association of anemia with CKD: A hospital-based cross-sectional study from Nepal. Biomedical Research 2013; 24 (1): 99-103.

13. KDIGO Anemia Work Group. KDIGO Clinical practice guideline for anemia in chronic kidney disease. Kidney Int Suppl. 2012; 2:279-335

14. Li Y, Shi H, Wang W, Peng A, Jiang G, Zhang J et al. Prevalence, awareness, and treatment of anemia in Chinese patients with nondialysis chronic kidney disease. Medicine. 2016;95(24):e3872.

15. Mehdi U, Toto R. Anemia, Diabetes, and Chronic Kidney Disease. Diabetes Care. 2009;32(7):1320-1326.

16. Loutradis C, Skodra A, Georgianos P, Tolika P, Alexandrou D, Avdelidou A et al. Diabetes mellitus increases the prevalence of anemia in patients with chronic kidney disease: A nested case-control study. World Journal of Nephrology. 2016;5(4):358.

17. Salifu M, Batuman V, Delano B. Chronic Glomerulonephritis: Practice Essentials, Pathophysiology, Etiology [Internet]. Emedicine.medscape.com. 2018. Available from: https://emedicine.medscape.com/ article/239392-overview

18. Musti IGBDP, Duarsa GWK, Mahadewa TG, Wirata G. 2019. Berat badan lahir lebih dari 4000 gram merupakan faktor risiko kejadian mikropenis pada bayi baru lahir di Denpasar tahun 2019. Intisari Sains Medis 10 (3): 604-607. DOI: $10.15562 /$ ism.v10i3.577

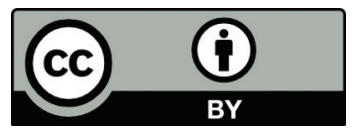

This work is licensed under a Creative Commons Attribution 